IRA-International Journal of Education \& Multidisciplinary Studies

ISSN 2455-2526; Vol.07, Issue 03 (2017)

Pg. no. 210-214

Institute of Research Advances

http://research-advances.org/index.php/IJEMS

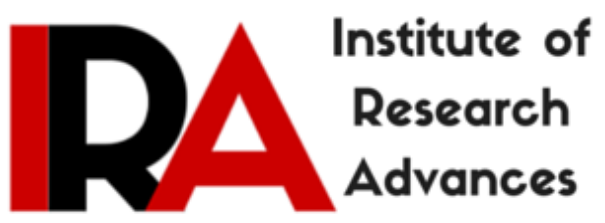

\title{
Addiction Eradication: A Systematic Approach to Save New Generation
}

Dr Devendra Kumar Pandey

Associate Professor, Amity University, Gwalior, INDIA.

Type of Review: Peer Reviewed.

DOI: http://dx.doi.org/10.21013/jems.v7.n3.p5

\section{How to cite this paper:}

Pandey, D. (2017). Addiction Eradication: A Systematic Approach to Save New Generation. IRA International Journal of Education and Multidisciplinary Studies (ISSN 2455-2526), 7(3), 210214. doi:http://dx.doi.org/10.21013/jems.v7.n3.p5

(C) Author.

\section{(c) EY-NC}

This work is licensed under a Creative Commons Attribution-Non Commercial 4.0 International License subject to proper citation to the publication source of the work.

Disclaimer: The scholarly papers as reviewed and published by the Institute of Research Advances (IRA) are the views and opinions of their respective authors and are not the views or opinions of the IRA. The IRA disclaims of any harm or loss caused due to the published content to any party. 


\begin{abstract}
The article elaborates the menace of Tobacco/drug addiction. Tobacco is considered as the first step towards any drug addiction. Tobacco kills more than tuberculosis, HIV/AIDS and malaria combined. $71 \%$ of all Lung cancer deaths are attributable to tobacco use. The proposed "Simplified Addiction Trap Model" highlights the process of addiction. By implementing the suggested low cost model, the addiction can be eradicated in new generation which will ultimately result in total addiction eradication in coming years.
\end{abstract}

Keywords: Tobacco, Drug, Addiction, De-addiction, WHO, Public health.

Tobacco consumption is a critical problem to the economic and social development around the world. It is the main source of preventable deaths worldwide. Smoking-related ailments cost billions of dollars every year, levying heavy monetary toll on nations, due to expensive medical treatments and lost productivity/opportunities. Due to ill effects of tobacco, people loose efficiency and life in their early years.

As per WHO Framework Convention on Tobacco Control "the spread of the tobacco epidemic is a global problem with serious consequences for public health that calls for the widest possible international cooperation and the participation of all countries in an effective, appropriate and comprehensive international response. Every person should be informed of the health consequences; addictive nature and mortal threat posed by tobacco consumption and exposure to tobacco smoke and effective legislative, executive, administrative or other measures should be contemplated at the appropriate governmental level to protect all persons from exposure to tobacco".

Article 8 of the WHO Framework Convention on Tobacco Control states:- ... logical evidences have clearly proved that tobacco consumption/exposure causes disease, disorders and pre-mature deaths. According to WHO Global report, deaths related to Tobacco; globally $12 \%$ of all deaths among grown-ups of 30 years and above were due to tobacco consumption. Around 6 million adults of 30 years and above die every year due to tobacco consumption. This means on an average one tobacco related death takes place in every five seconds. Tobacco use is the most important risk factor for cancer and is responsible for approximately $22 \%$ of cancer deaths. Almost all the countries are facing the problem of tobacco addiction and its negative impact on new generation and society. Same report reveals that around 54\% world population is in the age group of 0-29 years. If we are able to educate this population effectively, statistically we can conclude that the rate of Tobacco related mortality can be reduced by $50 \%$.

Tobacco is considered as the first step towards any drug addiction. Young children generally start experimenting easily available Tobacco products for intoxication. These experiments occur due to curiosity or due to peer pressure. When they become habitual of tobacco, they go for more complex drugs. If they are sensitised about the addiction trap and are mentored through their parents and teachers, they will surely give a second thought before starting tobacco consumption. If they do not fall in the trap of tobacco, they will surely not go for complex drugs.

\title{
Objective
}

1. To stop addition of new cases of addiction by concentrating on young children.

2. To develop an easy to understand simplified model for Tobacco Addiction Trap which leads to other complex addictions in future.

3. To sensitise students, parents and teachers about the Tobacco addiction trap though displays on School notice boards.

4. To sensitise Governments for adopting policies which ensure spread of this model among all stakeholders i.e. students, parents and teachers.

5. To sensitise various agencies to spread Addiction Eradication campaign using this model. 
6. To achieve reduction in Tobacco consumption by new generation.

\section{Methodology}

Catch them young is the key word for proposed model. All school going children should be made aware of the 'addiction trap', through targeted efforts. Since Parents and Teachers are the stakeholders in development of will power against addiction, they should also be made to understand the 'addiction trap' through following model (figure 1):

Addiction eradication through mass awareness campaign

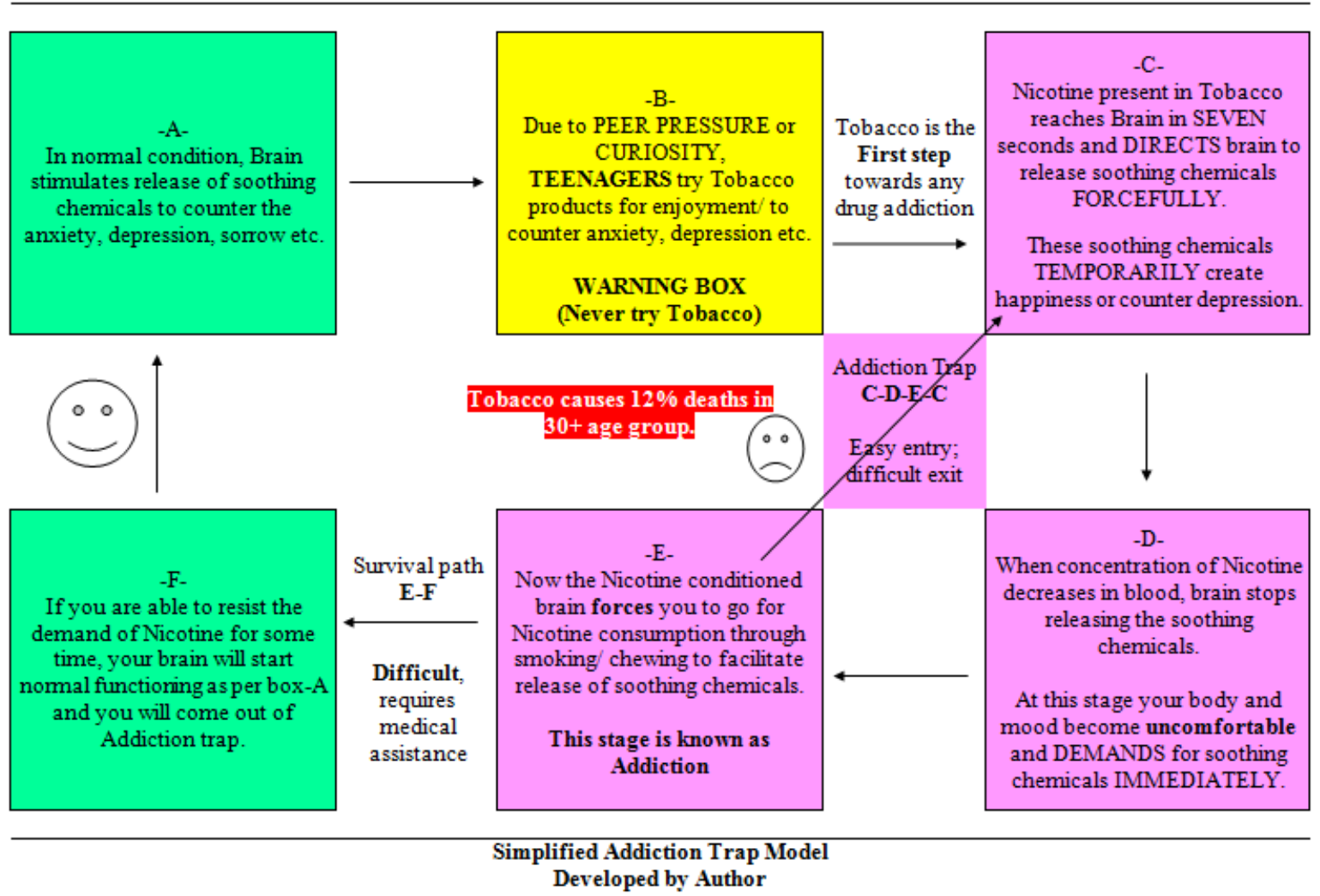

Figure 1: Source-Developed by author.

This low cost model needs to be displayed through a printed Flex/Posters. Display should be as under:

$\checkmark$ Next to the main notice board of school/ Village offices. Size of the printed flex should not be less than the size of Notice board, to get the maximum attention.

$\checkmark$ At the waiting area for parents. When parents will observe these displays during their routine visits to school, they will try to practice themselves and mentor their wards for not falling in the addiction trap.

$\checkmark$ Flex/poster cost: Hardly $\$ 10$ per school, which can be funded by Schools itself, local bodies, trader community, parents association etc.

$\checkmark$ Educate the children in early age about the Tobacco addiction process. They should be exposed to and explained the Addiction Trap Model.

$\checkmark$ In exams there should be 1-2 questions from this Model. Once in a year they should also be asked to draw the complete model.

$\checkmark$ At the time of admission in any class, during interaction with parents, they should be asked to draw the Addiction Trap Model. 
$\checkmark \quad$ All the competitive exams should contain 1-2 questions from Addiction Trap Model.

$\checkmark$ During teachers' recruitment and all annual appraisals they should be asked to draw the complete model.

$\checkmark$ Model should also be displayed on all the public places where young children are likely to visit.

\section{Conclusion}

At Addiction stage individuals are aware that they do not "need" the drug, but survival drive dominates the logic. Once new generation is sensitised against the tobacco menace and they resolves against addiction firmly, objective of addiction eradication in all age groups could be achieved in few years.

\section{References}

1. Non-communicable Diseases Country Profiles 2014. Available on http://apps.who.int/iris/bitstream/10665/128038/1/9789241507509_eng.pdf. Visited on 4-32017

2. Tobacco - Fact sheet. Available on http://www.who.int/mediacentre/factsheets/fs339/en/. Visited on 4-3-2017.

3. WHO Global report, Mortality Attributable to Tobacco. Available on http://www.who.int/tobacco/publications/surveillance/fact_sheet_mortality_report.pdf. Visited on 4-3-2017.

4. WHO Global report, Mortality Attributable to Tobacco. Available on http://apps.who.int/iris/bitstream/10665/44815/1/9789241564434_eng.pdf. Visited on 4-32017.

5. WHO Report on the Global Tobacco Epidemic-2015, Raising Taxes on Tobacco. Available on http://apps.who.int/iris/bitstream/10665/178574/1/9789240694606_eng.pdf?ua=1\&ua=1. Visited on 4-3-2017. 
Addiction eradication through mass awareness campaign

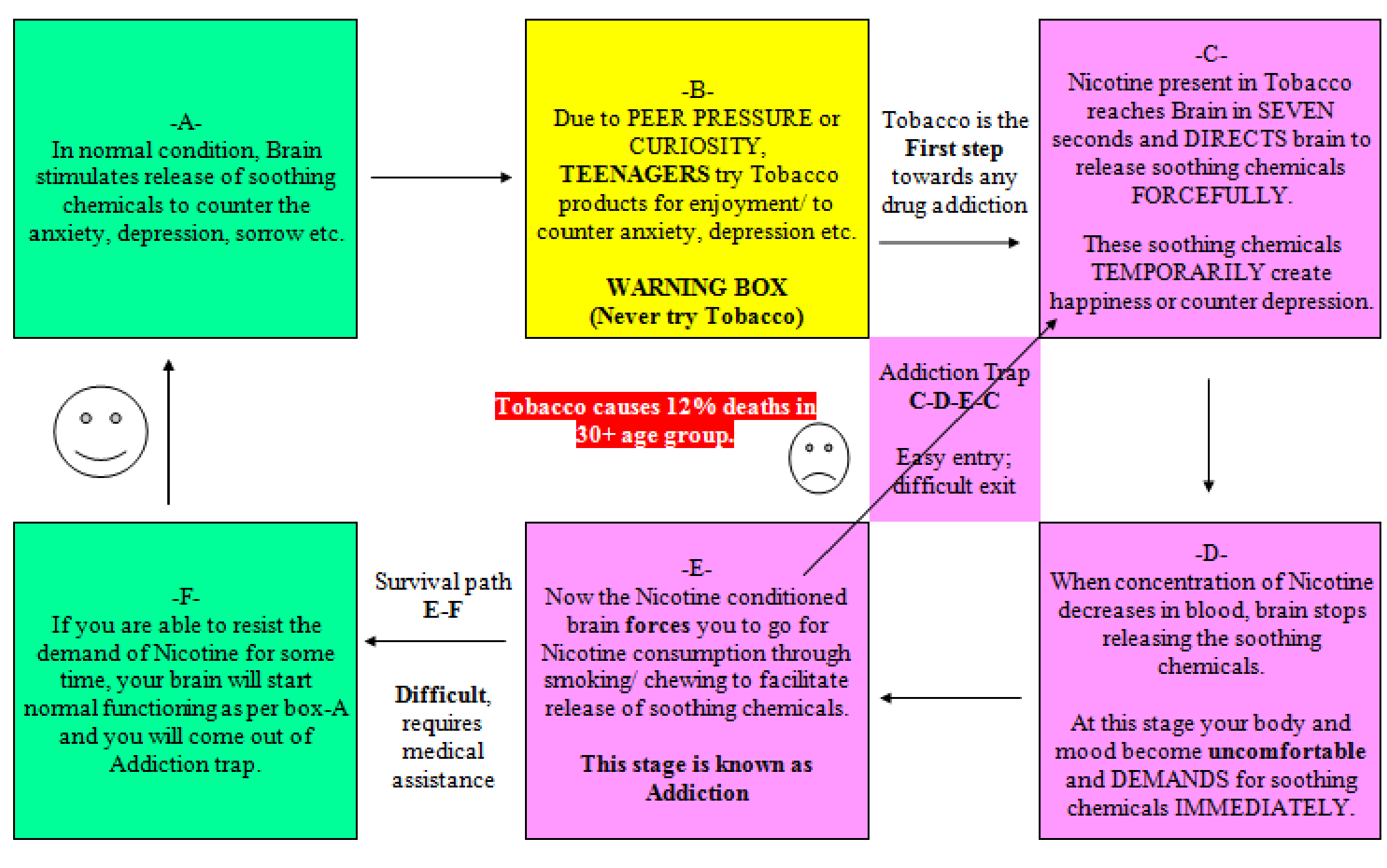

Simplified Addiction Trap Model

Developed by Author 